\title{
Creencia y pertenencia: El laberinto de las sociedades posotomanas
}

DOI: $10.15175 / 1984-2503-202113301$

\author{
Samer ALNASIR* \\ Lo político es solo una faceta de lo social. \\ (ORTEGA Y GASSET, 1921, p. 31)
}

\begin{abstract}
Resumen
La coagulación poscolonial es el dilema de muchas sociedades que no terminan de formarse debido a las crónicas secuelas del colonialismo y el dominio de la colonialidad. Más aún, cuando estas secuelas se han convertido en un laberinto inacabable para la antropología político-islámica y concretamente para la árabe. El presente estudio se propone, primero, para analizar la emergencia de las religiones abrahámicas entre las tribus árabes y su papel para suplantar el canon de la identidad y la pertenencia, formando un patrón universal de identidad jurídica sustancialmente diferenciado del europeo, y derribando el antiguo concepto tribal. De ahí se pasa a analizar la formación de la ideología islámica como derecho positivo mediante un paralelismo empírico con el derecho romano, introduciendo para ello el concepto latino interpolare. Así, llegaremos a la conclusión de cómo la interferencia extranjero-colonial jugó el papel principal en diluir el canon identitario y el de pertenencia, creando una identidad postiza, faroleada y conforme a las avenencias coloniales, envolviendo la epistemología religiosa en un sistema normativo forzado que causó la esquizofrenia y la resistencia cognitiva al poder y la desobediencia normativa, fomentando incluso la esquizofrenia y la aversión a la realidad.
\end{abstract}

Palabras claves: identidad postraumática; política postraumática; laberinto de identidad y pertenencia; esquizofrenia poscolonial; camuflaje identitario.

\section{Crença e pertencimento: O labirinto das sociedades pós-otomanas}

\section{Resumo}

A coagulação pós-colonial é o dilema de muitas sociedades que não concluíram a sua formação, devido às sequelas crônicas do colonialismo e ao domínio da colonialidade. E isso com ainda maior ênfase, já que essas sequelas se tornaram um labirinto sem fim para a antropologia político-islâmica e, especificamente, para a árabe. Em primeiro lugar, o presente estudo se propõe a analisar o surgimento das religiões abraâmicas entre as tribos árabes e o respectivo papel na suplantação do cânone de identidade e pertencimento, formando um padrão universal de identidade jurídica substancialmente diferente do europeu, e derrubando o antigo conceito tribal. A partir daí, analisa-se a formação da ideologia islâmica como direito positivo, mediante um

\footnotetext{
* Profesor Asociado en Historia del Derecho de la Universidad Carlos III de Madrid. Doctorando en Filosofía Ética y Política en la Universidad Nacional de Educación a Distancia. Máster en Protocolo en la Universidad Nacional de Educación a Distancia. Máster en Derecho Público en la Universidad Carlos III de Madrid. Máster en Filosofía del Derecho en la Academia Europea de Teoría del Derecho, Bruselas, y DEA en Derecho administrativo en la Universidad CEU San Pablo. Ex. Miembro de la comisión constituyente de Iraq. Ex. Asesor de la Corte Penal especial de Iraq. E-mail: samer@alnasir.org. (1) https://orcid.org/0000-0002-9232-9035
} 
paralelismo empírico com o direito romano e introduzindo, para tanto, o conceito latino interpolare. Assim, chegaremos à conclusão de como a interferência estrangeira-colonial desempenhou papel principal na diluição dos cânones identitário e de pertencimento, criando uma identidade postiça, falseada e conforme aos compromissos coloniais, envolvendo a epistemologia religiosa em um sistema normativo forçado, causador da esquizofrenia e da resistência cognitiva ao poder, assim como da desobediência normativa, e favorecedor, inclusive, da esquizofrenia e da aversão à realidade.

Palavras-chave: Identidade pós-traumática; política pós-traumática; labirinto de identidade e pertencimento; esquizofrenia pós-colonial; camuflagem identitária.

\title{
Belief and belonging: The labyrinth of post-Ottoman societies
}

\begin{abstract}
Post-colonial coagulation is the dilemma of many societies in endless formation due to the aftermath of colonialism and the dominance of coloniality, and even more so when this aftermath has been converted into a never-ending labyrinth for political-Islamic anthropology, particularly in the Arab case. The present study primarily aims to analyze the emergence of Abrahamic religions among Arab tribes and their role in supplanting the canon of identity and belonging, forming a universal standard for legal identity substantially different from the European one, and overturning the ancient tribal concept. The study then shifts to analyzing the formation of Islamic ideology as positive law by means of an empirical parallelism with Roman law, thus introducing the Latin concept of interpolare. We therefore arrive at the conclusion of how foreign-colonial interference played the main role in diluting the identity canon and that of belonging, creating a false identity, shaped to conform to colonial compromises, wrapping religious epistemology in a forced normative system to have caused schizophrenia and cognitive resistance to power and normative disobedience, even prompting schizophrenia and an aversion to reality.
\end{abstract}

Keywords: Post-traumatic identity; post-traumatic policy; labyrinth of identity and belonging; postcolonial schizophrenia; identity camouflage.

\section{Croyance et appartenance : le labyrinthe des sociétés post-ottomanes}

\section{Résumé}

La coagulation postcoloniale constitue le dilemme de nombreuses sociétés qui n'ont pas pu terminer de se former en raison des séquelles chroniques du colonialisme et de la domination de la colonialité. Et plus encore lorsque ces séquelles se sont transformées en un labyrinthe interminable pour l'anthropologie politico-islamique, et plus spécifiquement arabe. La présente étude propose dans un premier temps d'analyser l'émergence des religions abrahamiques parmi les tribus arabes et leur rôle dans la substitution des canons d'identité et d'appartenance de l'époque par un standard universel d'identité juridique substantiellement différent de l'européen et terrassant au passage l'ancien concept tribal. Nous analyserons ensuite la formation de l'idéologie islamique en tant que droit positif à travers un parallélisme empirique avec le droit romain, ce pour quoi nous introduirons le concept latin interpolare. Nous arriverons ainsi à notre conclusion selon laquelle l'interférence coloniale a joué un rôle essentiel dans la dilution des canons d'identité et d'appartenance pour créer une identité aussi fausse qu'artificielle conforme aux compromis coloniaux et englobant l'épistémologie religieuse dans un système normatif forcé qui provoquera résistance cognitive au pouvoir et désobéissance normative, allant jusqu'à favoriser la schizophrénie et l'aversion à la réalité.

Mots-clés : Identité posttraumatique ; politique posttraumatique ; labyrinthe identitaire et appartenance ; schizophrénie postcoloniale ; camouflage identitaire. 


\section{信仰与归属：后奥斯曼社会的迷宫}

\section{摘要}

后殖民的遗存与凝固是许多殖民地国家独立之后所长期面临的困境。这些国家经历了殖民主义的长期统治，其 后果和维持到现在，并且以各种方式在后殖民时代逐渐凝固下来，阻碍这些国家的自主发展。这些殖民遗存与 凝固是伊斯兰政治人类学，特别是阿拉伯政治人类学的没完没了的迷宫。本研究首先分析了亚伯拉罕宗教在阿 拉伯部落中的出现及其在提供身份认同，社会归属、法律身份的作用。这种亚伯拉罕宗教-伊斯兰教推翻了古 老的阿拉伯部落概念，形成了伊斯兰意识形态与法律观念。与此同时，因为殖民统治的存在，罗马法原则被奥 斯曼帝国引进吸收，由此，拉丁文化插入了奥斯曼帝国内阿拉伯-伊斯兰文化。因此，我们得出结论，外国殖 民势力干涉奥斯曼帝国的过程中，殖民文化淡化了阿拉伯民族身份认同，淡化了伊斯兰经典所产生的精神归属 感，创造了一种符合殖民现实的虚幻身份，并将殖民主义认识论纳入宗教与政治规范体系。这种状况导致奥斯 曼帝国范围内，伊斯兰世界的精神分裂症和对权力和规范的不服从，以及对权力从认知角度进行抵抗。这种抵 抗加深了后奥斯曼社会的精神分裂症，并产生了对现实的厌恶。

\section{关键词：创伤后认同；创伤后政治；身份和归属的迷宫；后殖民精神分裂症；身份伪装。}

\section{Introducción}

La querella de la reconstrucción poscolonial ${ }^{1}$ ha sido el dilema de muchas sociedades. Las más estudiadas de ellas han sido las africanas, es decir, las residuales del colonialismo francés entendidas como sociedades mutantes (HENRY, 1984) o referidas como OPI, esto es, objetos políticos indeterminados (en francés, objets politiques non identifiés, OPNI) (MARTIN, 1989), o como una ficción social heterogénea (société composite) (BOUDERBALA; PASCON, 1970). Incluso después de décadas de independencia, y hasta después de las recientes revueltas del siglo XXI se siguen definiendo como naciones no-localizables, un-retrievable nations (ALLAL; GEISSER, 2011). ${ }^{2}$ Sin embargo, hasta el momento no se han realizado estudios introspectivamente interdisciplinares sobre las sociedades posotomanas afectadas indirectamente por el colonialismo anglofrancés, y convertidas en escenario de conflicto delegado entre las potencias, ni en cuanto a la instrumentalización colonial de la/su religión y las secuelas de los conflictos delegados entre las potencias

\footnotetext{
${ }^{1}$ Por colonos, o fuerzas coloniales, de aquí en adelante, se hace referencia a todas las fuerzas extranjeras que invadieron, dominaron y sometieron a los pueblos referidos, desde los tártaros que derrotaron al Imperio abasida en 1256, pasando por los otomanos, hasta el colonialismo europeo y, recientemente, el norteamericano.

${ }^{2}$ El adjetivo de no-localizables (un-retrievable) se refiere a la base popular de los partidos políticos del mundo árabe, en alusión concreta, por Allal y Geisser, a los partidos políticos tunecinos. La propuesta de este artículo es extender el mismo adjetivo a todo el conjunto sociopolítico árabe, no solamente compuesto por partidos de naciones no localizables, sino también por Estados con naciones no localizables, o hasta por pueblos de naciones no localizables.
} 
coloniales. No obstante, varios estudios sobre el colonialismo británico se han proyectado desde la perspectiva alabadora y elogiadora de sus logros como embriones de la civilización y el desarrollo colonial (SATIA, 2007, p. 214) y propulsores del progreso (CONSTANTINE, 2005), impulsores de identidad (LEED, 1979) o patronos de la tecnocracia colonial (MITCHELL, 2012), entre otros. ${ }^{3}$

El presente estudio se propone introspectivamente para analizar la construcción sociocognitiva de los colectivos orientales, tomando como referencia, concretamente, el caso de Iraq, debido a múltiples razones. Primero, Iraq ha sido el primero y el más relacionado con el Imperio otomano debido a su posición geográfica, es el colindante inmediato y paso franco para el resto de las provincias otomanas, por tanto, y es la segunda razón, ha sido el primero en ser colonizado por los otomanos desde el siglo XV y hasta el derrumbe de su imperio por la Primera Guerra Mundial. Y, en tercer lugar, debido a sus condiciones históricas, la cuenca de la Mesopotamia representa la confluencia antropológica más antigua, más allá del escenario nómada de la península arábiga. $Y$, además de todo ello, por ser el escenario de la disputa colonial entre las potencias otomano-británicas, tanto de forma indirecta, como se explorará en el presente artículo, como en la forma directa y militarmente decisiva. En Iraq el ejército británico sufrió su más humillante derrota nunca documentada desde Yorktown en 1781, y nunca vista después hasta la caída de Singapur en 1942 (POPPLEWELL, 1990, p. 139), y en el sentido contrario, allí transcurrió la batalla más inmensa y decisiva de la Primera Guerra Mundial para la consecuente derrota otomana, que originó su posterior capitulación.

Metodológicamente, se evitará referirse a las comunidades, los grupos o los pueblos involucrados como sociedades, dado que la perspectiva desde la que se formula el presente es negarles esa categoría social, ya que se aborda el problema de su identidad y pertenencia como esquizofrenia identitaria. Y dado que, no habiendo identidad, no hay entidad (BÉZIAU, 2003; PARSONS, 1987; QUINE, 1960), se evitará esa categoría de equivalencia utilizando cualquier otro término individualizante para resaltar la carencia categórica. Además, por razones de extensión, se evitará verter referencias o análisis en cuanto a la definición

\footnotetext{
${ }^{3}$ En resumen, el poscolonialismo francés se proyecta arraigando la negación y el británico opta por la alabanza y el saneamiento-blanqueamiento de la historia. El posfrancés para negar la existencia previa de las estructuras sociales y políticas anteriores a la colonización, para justificar que hayan sido colonizados por causa de su salvajismo, que es la ideología francmasona dominante desde la Revolución francesa, y el británico expulsando la negatividad y adoptando la narrativa de la literatura del elogio y la alabanza. Es decir, como bien describió Bayart, un carnaval académico (BAYART, 2010a, 2010b) que de pronto se ha convertido en el síntoma mediócrata de la academia occidental (DENEAULT, 2015).
} 
de la identidad o la pertenencia, y su papel psicosocial o sociopolítico en el forjamiento grupal, limitando así la exposición a una exhibición empírica.

En cuanto a la transliteración de los nombres propios al latín, se hará gracias a la plataforma Lexilogos para aquellos nombres desconocidos, o directamente se manejará su equivalente conocido en Google Scholar. Además, al referirse a pueblos, naciones o países, de aquí en adelante se abordará su ordenación alfabéticamente.

Para los términos «colonialismo» y «colonialidad» nos atenemos principalmente al esquema propuesto por Maldonado-Torres $(2007$, p. 131) en cuanto a que:

\begin{abstract}
Colonialismo denota una relación política y económica, en la cual la soberanía de un pueblo reside en el poder de otro pueblo o nación, lo que constituye a tal nación en un imperio. Distinto de esta idea, la colonialidad se refiere a un patrón de poder que emergió como resultado del colonialismo moderno, pero que en vez de estar limitado a una relación formal de poder entre dos pueblos o naciones, más bien se refiere a la forma como el trabajo, el conocimiento, la autoridad y las relaciones intersubjetivas se articulan entre sí, a través del mercado capitalista mundial y de la idea de raza.
\end{abstract}

Quijano, por su parte, entendió la colonialidad como eurocentrismo hegemónico cultural y poder de seducción populista universal que arrasó las identidades nativas del mundo, un modo de dominación en sustitución del modelo de colonialismo clásico asentado desde el siglo XV (QUIJANO, 1992, p. 12-14). Sin embargo, en las perspectivas del presente, se propondrá definir la colonialidad como secuela camuflada, un caballo de Troya introducido dentro de las estructuras antropológico-cognitivas de los pueblos para ser agarrado artificiosa-faroleadamente como referente identitario (anti)colonial.

\title{
De la esquizofrenia identitaria a la política postraumática
}

Oriente Medio, escribe HEIKAL (1958), ha sufrido multitud de conflictos, conspiraciones, influencias, e invasiones bárbaras que acumularon un sinfín de traumas, fracturas y secuelas que se envolvieron con las estructuras antropológicas y se arraigaron en las mentes de los pueblos y sus líderes emergentes, que cargan con toda esa constelación de traumas y que afectan hoy a sus formas de actuar y hacer política. Los problemas de la actuación política, por tanto, se deben a esta constelación cognitiva que impone y articula un laberinto de política problemática, de política postraumática (HEIKAL, 1958). 
Las sociedades latinas ${ }^{4}$ han sido construidas sobre el concepto de incorporaciones (ORTEGA Y GASSET, 1921, p. 8), basadas en compartir vecindad, principalmente por interés geoestratégico y mediante un synoiquismo, ${ }^{5}$ un ayuntamiento de moradas. Existe un paradigma más antropológico que jurídico en su construcción social, que gira en torno a una factualidad jurídica, y que ha llenado el vacío cultural, compuesto por la tierra, el tiempo y la sangre (GROSSI, 2007, p. 25 et seq.). La tierra como valor inamovible de pertenencia, y tangible de posesión-propiedad, y, por tanto, bien económico; la sangre como constelación antropológica de cohesión subjetivo-individual; y el tiempo como factor de progreso y arraigo de la cohesión intergeneracional. Este paradigma, en comparación con las colectividades árabes, o concretamente las de nuestro ejemplo, es inaplicable.

Las comunidades del centro-sur de la península arábiga eran nómadas, precisamente su nomadismo se debe a la búsqueda constante de fuentes de pastoreo, por tanto, ni existe el vínculo con la tierra como arraigo ni es el principal bien económico ni jurídico de propiedad, sino que lo es el ganado, su comercio y lo que de ello se sirva. Por tanto, el anclaje, tanto entra como intergrupal es líquido, al igual que el arraigo territorial, determinada por el tiempo, las condiciones espacio-temporales del pastoreo, su comercio, las estaciones del año y las condiciones climatológicas, que de una forma u otra condicionan la política del más fuerte en cada momento. En cambio, las mesopotámicas sí contaban con el factor tierra, como recurso económico y también como valor de posesión, pero también líquida, ya que, debido a la concentrada fertilidad de ese recurso, ha sido objeto de constantes invasiones y sumisiones que hicieron difícil definir concretamente su poseedor real. La tierra y sus riquezas se han convertido en un legado intergeneracional de pertenencia mestiza, cada siglo, cada milenio pertenece a una etnia distinta resultante de la composición de las anteriores y todo el legado histórico que hayan dejado a su paso. La tierra se ha vuelto objeto de pertenencia temporal, por volverse, a su vez, en objeto de conflicto, de atracción extranjera y de consecutivas invasiones, en paradigma de pertenencia punzante más que de arraigo e identidad, como lo fue para Europa. Lo mismo ocurre con la sangre,

\footnotetext{
${ }^{4}$ Con sociedades latinas nos referimos a las romano-germanas, a excepción de la española, por tener esta otra fórmula distinta que se sale de las dimensiones de este artículo, y la propia referencia de Ortega y Gasset y de Grossi.

${ }^{5}$ El término «synoiquismo» se introduce al castellano por Ortega refiriéndose a Mommsen, que lo hace en alemán como término derivado del synoikismós griego, el ayuntamiento de moradas, es decir, como sistema de incorporación social de las naciones. En la edición francesa del trabajo de Mommsen, dice Ortega y Gasset, optó por referirse a ello como «sistema de incorporaciones», expresión menos técnica; sin embargo, Ortega y Gasset opta por introducir el mismo concepto al castellano, synoiquismo.
} 
debido a la constante movilidad etnográfica derivada de las invasiones y las sumisiones al extranjero, no existe ni línea de consanguinidad ni un tronco genealógico continuo. Las invasiones, las conversiones y las huidas, los exilios y las imposiciones acabaron convirtiendo el grupo en una comunidad mestiza, heterogénea y carente de un patrón de unidad racial o sanguínea, corresponde más a una concreción cosmopolita que metropolitana. El tiempo, por tanto, se convierte en valor de suma cero, irrelevante para conformar ningún arraigo o enlace de los anteriores.

El hecho primario social, dice Ortega y Gasset, no es la mera reunión de unos cuantos hombres, sino la articulación que en ese ayuntamiento se produce inmediatamente (ORTEGA Y GASSET, 1921, p. 31). Y, en este caso, la forma de reunión, el aglutinamiento, es el principal impulsor para sostener la articulación y, a la inversa, es el principal motivo para causar la disolución, confrontación o esquizofrenia. A continuación, pasaremos a analizar la génesis de la unión de los grupos orientales como una particularidad singular ajena al paradigma europeo hasta ahora conocido.

\section{La creencia como identidad}

La emergencia de las religiones y su rotación sobre el tiempo ha sido el factor determinante y más estable de la identidad grupal, pero, a su vez, la más desafiante de las estructuras sociales y estamentales, porque las religiones se han constelado en el único vínculo de identidad y pertenencia grupal. El synoiquismo árabe se formó en torno a las creencias religiosas. Las tribus se interpelaban y se identificaban sobre la base de los dioses que adoraban, e involucrarse con ellas, con las tribus, tanto en alianzas antropológicas como en moradas, estaba condicionado por la adoración de los demás dioses con los que se identificaban los otros. La deidad responde a un patrón de equivalencia identitaria del sujeto al grupo, a alianzas y a una ley de cohesión extra e intergrupalmente.

He aquí un diferencial importante en el paradigma. La filosofía grecorromana se basaba en la deidad asistencial, es decir, el dios del mar para los marineros, el de la caza para los cazadores, el de la lluvia para los agricultores, el de la guerra para los guerreros, etc. Esa fórmula del dios asistencial impregna un arsenal mítico de ese dios, como un ser último omnipotente por sí mismo. El icono mítico de ese dios era definido y representado como el conjunto de su ente en sí mismo. Sin embargo, el abrahamismo es globalmente diferente, al imponer una sola deidad única y omnipotente, que fue posteriormente referida por otros dioses menores 
como intercesores ante dicho dios único y todopoderoso. Es decir, algo similar a la fórmula católica actual, un Dios padre ante quien intercede la comunión de los santos.

Las tribus árabes, por tanto, inventaban figuras, iconos con los que se identificaba a los dioses, pero no por sí mismos, sino como figuras intercesoras ante el Dios omnipotente. La utilidad de estos iconos por sí misma se entendía como identidad y pertenencia, cada grupo se identificaba por medio su intercesor, convencido de que el suyo era el más vigoroso y mejor intercesor ante el Dios último. La creencia iconográfica, por tanto, responde a un esquema de distintividad, a una identidad distintiva ${ }^{6} \mathrm{y}$, además, difusa entre cada uno de los individuos y la tribu misma, ya que el elemento forjador ${ }^{7}$ de la tribu es constantemente representativo mediante esa deidad iconográfica, por ello la identidad individual se convierte en colectiva y, por ende, en colectividad individual.

La emergencia del catolicismo entre las sociedades grecorromanas no ha afectado a la pertenencia en sí por alterar ligeramente el esquema de los iconos de los dioses últimos por la de los santos e intercesores ante un Dios último, ya que, en todo caso, ninguno supone un símbolo de identidad ni de pertenencia, sino simplemente un paradigma asistencial y auxiliar mítico. En cambio, la emergencia entre los pueblos árabes, tanto judíos y cristianos $^{8}$ como posteriormente musulmanes, supuso un golpe radical y destructor de todo el paradigma de identidad y pertenencia grupal. Al suprimir/sustituir los iconos subjetivos, tribales, por otros ecuménicos, tanto la identidad como la pertenencia dejan de tener concepto, y los grupos, por tanto, quedan anclados a otro concepto de identidad, el de la religión misma y en su conjunto. ${ }^{9}$

\footnotetext{
${ }^{6}$ Tajfel (1981, p. 254) asentó la definición de la distintividad, distinctiveness, como uno de los elementos cardinales de la identidad psicosocial formada por la categorización social, la identidad social, la comparación social y la psicología grupal distintiva.

${ }^{7}$ Forjando naciones, o patrias, es una idea propuesta por Gamio (1982) desde una perspectiva de construcción étnico-racial indígena seguida de la revolución mexicana, véase Castillo Ramírez (2013).

${ }^{8}$ Con cristiandad se hace referencia a la cristiandad oriental genuina, ajena a las oligarquías grecorromanas emergentes en Europa, como el catolicismo.

${ }^{9}$ Esto explica que el jaque que supone la aparición de las religiones en el mundo oriental es directamente combatido por las oligarquías políticas, así el faraón de Egipto con Moisés, Nabucodonosor y el cautiverio judío, Herodes y el nacimiento de Jesús... Al mismo tiempo, explica la distracción cristiana de la invasión del poder y su formación como ente bicéfalo apartado de la oligarquía política. Jesús primero ordena a sus partidarios que abandonen lo que tienen y que lo sigan (MATEO 19:21), sin embargo, posteriormente reconoce la continuidad de la oligarquía política: «Dad al césar lo que es del césar, y a Dios lo que es de Dios» (LUCAS 20:25).
} 


\section{El abrahamismo en Oriente}

Los pueblos abrahámicos ya obedecían a la deidad omnipotente. El Qurán corrobora en varios pasajes $(29: 61-63,31: 25,39: 38,43: 87)$ que los pueblos anteriores, concretamente los árabes, ya venían adorando al Dios omnipotente, el mismo Dios referido por todo el esquema abrahámico — judeocristiano- Sin embargo, contaban con un icono intercesor creado tangiblemente a los efectos de identidad y pertenencia, que era la definición de las tribus. Cada tribu tenía su intercesor propio y único ante el Omnipotente, con el que se identifican. La aparición del islam no solamente difumina la tangibilidad de los intercesores, sino que también aniquila el referente identitario que estos suponían para las tribus, y que a su vez era un elemento de fragmentación y segregación, que de pronto es sustituido por un solo elemento de identidad, pero también de unión y agrupación. Suprime, por ende, la propia esencia de las tribus como tales al integrar a todas en el pueblo, la nación islámica, universal y ecuménica. Una pertenencia ajena a todos los valores tangibles, ni sangre ni tierra ni tiempo influyente, ajena a toda entidad jurídica o económica, la fe se convierte en instrumento sociopolítico de identidad al portador, el mismo papel que anteriormente había desempeñado el judaísmo en el pueblo judío, inicialmente entendido como etnia semita, pero extendiendo después la identidad religiosa como constelación antropológica.

La creencia, y todo el conjunto pragmático que conlleva, se convierte en un esquema de aculturación identitaria, y simultáneamente de cohesión cívica y cosmopolita. Las tribus que se cuajaban a base de alianzas y avenencias líquidas, segregadas por la fe, pasan a un ayuntamiento de moradas bajo el paraguas de una creencia, pero esta vez única para todos, además de invisible e imaginaria. Es decir, no solamente cambia el esquema de representación, sino también la tangibilidad, la deidad iconográfica es arrebatada por una deidad única, exclusiva y excluyente de todas las demás, pero invisible e imaginaria, su representación es el paradigma que impone la unión de todos por ese esquema espiritual llamado islam.

La emergencia del monoteísmo islámico viene a imponer el fin de la circunscripción de la iconografía de los dioses, el fin de su materialización hacia una omnipotencia abstracta de un solo Dios que abarca todo el conjunto de la vida pública y privada, sustituyendo los varios dioses circunscritos a sus propios símbolos a favor de un solo Dios que se retira de la existencia para abarcar el existencialismo. De dioses presentes con circunscripción existencialista a otro único que abarca el conjunto del universo lógico, de dioses estatuarios a un Dios retirado de la existencia, pero estatutario, que cristalice una identidad que forje las 
tribus antagónicas, nómadas y desarraigadas. Por tanto, se plasma, por primera vez, como un referente de identidad, unidad, arraigo, paz y convivencia, en una configuración de la más alta libertad sociopolítica.

Las viejas tribus, seres, los Homo segmentatius ${ }^{10}$ o los grupos segmentados por los iconos-dioses intercesores pasan a formar la nueva comunidad-nación llamada nación islámica, es decir, la religión pasa a formar la construcción sociopolítica más allá de la antropológico-cognitiva. Sin embargo, el grado de penetración de ese nuevo paradigma depende del grosor/desarrollo de las viejas prácticas tribales, de ese grado de penetración —o la dimensión de las viejas prácticas- pasa a suponer el nuevo esquema de la segmentación, pero dentro de la misma pertenencia, la de la misma religión, segmentada —ahora- por los viejos usos antropológicos. Es decir, la nueva segmentación pasa a ser ideológica basada en el mismo referente, la religión.

Los Homo segmentatius de la antigua sociedad tomaban las leyes, los usos y las normas imperantes de sus antepasados. El corpus normativo social se formaba a través del bagaje de casuística y tradición acumulada por el pasado, que no se debían imperativamente al raciocinio lógico, ni mucho menos a la justicia, sino a la ponderación del más fuerte. El islam difumina, igualmente, este esquema y lo sustituye globalmente por una fuente inmediata, que es la revelación, y su interpretación profética. ${ }^{11}$ Es decir, el esquema de fuentes igualmente cambia a un esquema, en su momento, positivo, ya que tanto la revelación como su interpretación profética presentaba una fuente única para todos, uniforme y proveedora de soluciones que se iban surgiendo a lo largo de la vida profética formando simultáneamente un nuevo orden jurídico-moral y, con ello, una nueva identidad-pertenencia universal. El islam se enmarca y se define entre el antes y el después, definiendo a su antecesor como salvajismo y segmentación, y se proyecta para la unión y la cohesión.

Este sistema se mantuvo así, y con un similar afán, aunque con ciertas deserciones después de la muerte del Profeta, cuestión ajena al interés del presente discurso, hasta el derrumbe de Bagdad y, con él, del conjunto del Imperio islámico-abasí en 1256. Es decir,

\footnotetext{
10 Tomo prestado el concepto del Homo segmentatius de Abu-Lughod (1989, p. 280), aunque su idea de la segmentación se refiere a otro paradigma que el que aquí se propone.

${ }^{11}$ En la modernidad, Beccaria (1988, p. 62-63) entiende que "la voluntad de los sujetos vivientes mediada por el soberano: los jueces, no heredan las leyes de sus antepasados, sino que las toman de la sociedad o del soberano que representa a la sociedad como la voluntad de todos", según nota de Nousiainen (1997, p. 150). Es decir, en el momento de la comunión islámica, el concepto jurídico respondía, en cierta modo, a una modernidad jurídico-conceptual que sirvió globalmente para romper con el antiguo concepto jurídico-tribal, factual y segmentario de los Homo segmentatius para pasar a una nueva fórmula de positividad universal de la nueva nación compuesta por nuevos individuos integrados.
} 
la caída del Estado se tradujo, en cierta medida, en derrumbe y extinción del conjunto de la nación, de la identidad y la pertenencia que esto llevaba suponiendo para el conjunto del pueblo. Es cierto podría suponer lo mismo para cualquier otra nación, sin embargo, en este caso, el Estado representaba el canon moral y antropológico del pueblo. ${ }^{12}$ Los pueblos que se iban convirtiendo al islam, simultáneamente lo hacían subordinándose al Estado-nación que este venía expandiendo, el sistema de incorporaciones se basaba en la conversión, pero el derrumbe del Estado suponía la deserción cabal del conjunto del paradigma.

La definición del positivismo kelseniano de que «el orden normativo pierde su validez cuando deja de estar, en cierta medida, de acuerdo con la realidad (KELSEN, 2000) puede ser perfectamente aplicable aquí. La invasión tártara, aunque varias décadas más tarde se convierte al islam, supuso un derrumbe y el retorno a la vida segmentada, es decir, al tribalismo y a toda la factualidad normativa que aquel régimen imponía, incluso al nomadismo y el pastoreo por la huida de la metrópolis, saqueada y ensangrentada por los invasores. Por tanto, la invasión de Hulagu a Bagdad marca un antes y un después no solamente en el espectro político de la noción del Estado y el islam, sino también en todo el conjunto paradigmático de la identidad, la pertenencia, la moral y la normatividad islámico-ortodoxa, la cual pasa a ser un espejismo melancólico en la memoria antropológica de una nación que regresa a la segregación tribal y la segmentación del más fuerte. El regreso, además, no supone el retorno a la iconografía como identidad intercesora ante el Dios único, sino que es un retorno a ningún dios, un retorno a la vanidad ideológica e identitaria, y eso es algo que nunca había ocurrido. La nación islámica entra, por tanto, en un arquetipo de identidad diáfana y de esquizofrenia identitaria.

El nuevo arquetipo no supone una huida intencionada o premeditada, como lo habría supuesto en la sociedad occidental desde principios del siglo $\mathrm{XX}$, como un retorno a la vanidad de la ausencia de ningún dios (GALLEGO GARCÍA, 2005, p. 168) impulsada por la evolución, sino que es una huida impuesta, obligatoria y desesperada como consecuencia calamitoso-colonial. Esta estructura constituye un eje importante entre un paradigma voluntario y otro de exilio obligatorio impregnado en la identidad cognitivo-memorial anclada ansiosamente al espejismo del pasado asociado a la ortodoxia religiosa. Entender este

\footnotetext{
12 Algo equiparable a la leyenda de la Torre de Babel, según la cual la humanidad quedó segmentada por los múltiples idiomas que hablaba cada uno, diferenciándose de los demás, desplazando todo el esquema anterior de identificación.
} 
esquema es decisivo para entender la visión hacia la ortodoxia islámica como un espejismo y una aspiración última que se mantiene en el laberinto de la identidad hasta la actualidad.

Las sucesivas invasiones persas y otomanas (1258-1638), y desde entonces hasta el derrumbe del Imperio otomano en 1917, coagularon la comunidad en forma de segmentación tribal fragmentada. Cada tribu se convirtió en una entidad sociocultural y política independiente, incluso mutante, debido al nomadismo impulsado por el exilio grupal, más intensamente durante las invasiones persas y sus limpiezas ideológicas de los suníes de diciembre de 1624. ${ }^{13}$

Para poder entender el impacto de la neonormatividad islámica, y el curso del tiempo que afectó esa neonormatividad, y que después desempeñó el papel de instrumento exógeno-colonial, se expondrá a continuación la esencia normativa, y cómo esta pasó a ser elemento cardinal entre la nueva religión, el posterior Estado, y a proyectarse posteriormente por la nueva autocracia extranjera como instrumento político y de dominación, para invertirse finalmente y, de ser un instrumento de identidad, pasar a ser inductor de esquizofrenia.

\section{La neonormatividad de la doctrina islámica}

Como ya se comentó anteriormente, durante la vida profética, la sociedad islámica se regía por un ordenamiento positivo que se iba imponiendo mediante la revelación y las ordenanzas proféticas en forma de fuente soberana proveedora del derecho en la sociedad. Por ello, la muerte profética no suponía solamente el fin de la comunión, sino que también tiene un impacto inmediato en la normatividad social, ya que desaparece la fuente soberana y, con ella, la positividad. Los sucesivos cuatro regidores ejercieron la función de vicarios y sucesores de las enseñanzas proféticas. Es decir, la fórmula de los bien-guiados, entendidos como transmisores directos de los postulados y las enseñanzas proféticas, nombrados propiamente por el Profeta mismo con el fin de asentar la gobernanza en la sociedad. Pero el anuncio del primer sucesor marcó la línea divisoria al afirmar que «soy tan solo heredero del Profeta en el gobierno/poder, y no tengo nada que ver con la herencia de Dios» (ABDEL

\footnotetext{
${ }^{13}$ Durante los años de la regencia del Shah Abbas (1571-1629), el impulsor del shíismo en Irán e Iraq, y fundador del imperio safávida, se documenta el exterminio de más de un millón de personas, que fueron decapitadas a sangre fría, simplemente por negarse de maldecir a los tres primeros sucesores del Profeta conocidos como los bien-guiados-(COKE, 1927; LONGRIGG, 1925, p. 18 et seq.), suponiendo así el primer idiocidio-genocidio, shíi, muy escasamente documentado.
} 
RAZIQ, 1925, p. 97), entendiéndose desde entonces el fin de la profecía y el paso al nuevo concepto jurídico regido por la normatividad teocrática (ALNASIR, 2019, p. 32).

Las divergencias surgieron al fin del periodo de los bien-guiados, es decir, con la muerte del cuarto de ellos, y al pasar la soberanía al plebiscito popular. Según reiteraba el propio relato profético, «sus asuntos son decididos entre ellos» (QURÁN 42:38), y, por tanto, al no existir una norma marco para articular esa fórmula decisoria, emergió la confrontación para la sucesión.

El problema que nos interesa aquí no es el de la gobernanza, sino que, por la constitución del nuevo Estado, entendido como sucesor y continuación de los bien-guiados, y por la expansión social y los cambios a lo largo del tiempo, comienza a surgir la necesidad de una fuente de normatividad, ya que el nuevo Estado ostentaba el poder, pero no la fuente del derecho con la que contaba el anterior periodo profético. El nuevo Estado hereda el islam y sus enseñanzas, que se convierten en dogma, es decir, ostenta el paradigma, pero no la profecía, que se convierte en fuente interrumpida. Existe continuidad ideológica y espiritual, pero el fin de la vida profética y la de los bien-guiados marca la ruptura normativa. El nuevo Estado aboga por la identidad del islam, pero no ostenta la continuidad subjetiva, es un nuevo Estado nacido sobre el legado del otro, pero no exactamente una línea continua con este.

La era profética contaba con la revelación y las enseñanzas proféticas como fuente positiva, pero el nuevo apenas cuenta con aquella revelación y las enseñanzas pasaron a estancarse en textos herméticos que requieren sabiduría suficiente que abarque el conjunto, así como autoridad para interpretarlos conforme a su complejidad, la actualidad, además de establecer un esquema de concordancias. Ahí emergió la labor de los intérpretes, que sirvieron de iurisconsultos de la doctrina sagrada. Sin embargo, al depender la interpretación de distintas perspectivas, cada uno estableció una fórmula epistemológica de interpretación de los textos, que pasó a constituirse como escuela epistemológica, y en dicha interpretación empezaron a acumularse las interpolaciones realizadas que pasan a formar un corpus interpretativo ad hoc, es decir, neonormativo.

\section{Interpolaciones del derecho y la doctrina}

El término interpolación, del latín interpolare, se refiere a "refrescar algo que se ha ido quedando viejo e inútil para que valga como si fuera nuevo y sea útil otra vez" (KASER, 
1998, p. 17). ${ }^{14}$ Sin embargo, el concepto puede tener también connotaciones negativas, en el sentido de artimaña o manipulación. Para depurar el uso del concepto en el derecho romano, los cánones XVIII y XXV del Código Teodosiano del año 438 d. C. establecían que "para evitar interpolaciones [,] las leyes del emperador deberían ser recogidas en Códigos y publicadas en gran cantidad de ediciones" (KASER, 1998, p. 18). ${ }^{15}$ Tanto en la literatura como en la religión judeocristiana, por interpolación se entendía remontar los conceptos antiguos a la nueva dotación lingüística, a la nueva mentalidad, o afianzar los nuevos propósitos de uso (KASER, 1998, p. 19). Es decir, actualizar, reacomodar o reacondicionar. Ese mismo concepto fue el propulsor de la neonormatividad islámica que empieza a formarse entre varias perspectivas epistemológicas para esa interpolación a la que se denominó fiqh, es decir, exactamente lo mismo que en latín interpolare. ${ }^{16}$

Las interpolaciones formadas por las distintas perspectivas epistemológicas se fragmentaron globalmente entre dos bloques opuestos, debido al antagonismo metodológico postulado. Unos se aferraron a la ortodoxia como conservadores positivistas, mientras que otros lo hicieron a otros elementos hermenéuticos en una interpretación subjetiva teleológica como protesta al positivismo rigoroso.

El primero de los doctores de la nueva normatividad e interpolación islámica es original de Mesopotamia, natural de una ciudad apenas a un centenar de kilómetros de la antigua Babilonia, es decir, un babilónico, y no precisamente un árabe, dado que a la llegada del islam a las tierras mesopotámicas, es directamente puesto a examen. ${ }^{17}$ Abū

\footnotetext{
${ }^{14}$ Parece que la definición de la Real Academia Española (RAE) difiere de la que propone Kaser, que sí recoge la etimología latina, pero difiere en su actual uso en español, pues lo define como:

Del lat. interpolāre, 'recomponer, renovar', 'cambiar', 'intercalar'.

1. tr. Poner algo entre otras cosas.

2. tr. Intercalar palabras o frases en el texto de un manuscrito antiguo, o en obras y escritos ajenos.

3. tr. Interrumpir o hacer una breve intermisión en la continuación de algo, y volver luego a proseguirlo.

4. tr. Mat. Calcular el valor aproximado de una magnitud en un intervalo cuando se conocen algunos de los valores que toma a uno y otro lado de dicho intervalo.

${ }^{15}$ La coma de intersección es nuestra, ya que no aparece en el original, traducido del alemán del texto de Mommsen, quien lo traduce del latín: «Ne inttetpolentur constituta, plures codices fiant [...] ne constituta interpolentur, omnes codices litteris conscribantur».

${ }^{16}$ Fiqh desde el origen, e interpolare es el fruto. Es decir, fiqh, lingüísticamente, se refiere a meditar analíticamente sobre algo con sabiduría y epistemología predeterminada para obtener un resultado lógico aceptable. Propiamente se dice fiqh idiomático, es decir, 'entendimiento o conocimiento de un idioma', ya que entender un idioma supone conocer racionalmente su epistemología; fiqh del habla quiere decir 'el don de habla'. Interpolare, como ya se explicó algo más arriba, se refiere al resultado obtenido del conocimiento. Así, la aproximación aquí propuesta de entender el fiqh como interpolación, contextualmente se refiere a lo mismo, aunque en el fondo difiere en su proyección, uno es el origen metodológico y otro es el resultado.

17 Existe un abanico de negaciones en la literatura historiográfica oriental. Principalmente, el shíismo promueve la tesis negacionista del arabismo. Es decir, la academia shíi, principalmente la iraní y sus recientes filiales emergentes en Iraq, propulsan la literatura negacionista de que los principales patrones de la doctrina
} 
Ḥanīfah al-Nu'mān (699-767 d. C.) fue el primero en enfrentarse con la adaptación de la doctrina a los nuevos tiempos y a las nuevas tierras. Su epistemología, a la que se llamó racionalista, o hasta populista, posteriormente fue nombrada por antonomasia con el nombre propio de su fundador: escuela hanafí. El eje fundamental de su propuesta se refiere a introducir o añadir la razón como fuente del derecho para servirse de la analogía y proponer nuevas interpolaciones adaptadas espaciotemporalmente a cada caso y situación (' $L \bar{T}$; 'BD AL-'ZīZ, 2012, p. 43). Es decir, añadió fuentes secundarias al orden jurídico primario -el Qurán y las enseñanzas proféticas documentadas-, como la costumbre de la ciudad profética, y la razón como fuente de ponderación. La epistemología propuesta resultó ser popularmente bien recibida, más aún entre los nuevos pueblos, pero también resultó sugerente para que otros emergieran con otras perspectivas epistemológicas, y de ahí nacen las ramas de la doctrina islámica, cuestión que se sale del interés del presente artículo.

La protesta shíta emergió principalmente desde pulsiones políticas y luchas por el poder, la hegemonía y la denominación más propiamente que de postulados epistemólogodoctrinales, aunque es cierto que, en el fondo, también los contenían. Es decir, sí existían diferencias epistemológicas, pero estas nacieron propulsadas por contradicción, maldición, confrontación o búsqueda de una identidad diferenciada de los otros para zanjar la diferencia y situarse en el acervo beligerantemente adverso. En el aspecto epistemológico, y en lo que se refiere concretamente a nuestra comparativa, los shíitas introducen la interpolación como elemento clave condicionante para la vigencia de la normatividad islámica. Es decir, sin interpolación, la normativa primaria no tiene validez ante el pueblo hasta que haya sido interpolada, es decir, actualizada y puesta en contexto para su aplicación. Este esquema asocia el dogma y las enseñanzas al poder interpolador como fuente positiva, pero el problema tiene dimensión subjetiva. Así, los shíitas limitan el ejercicio del poder interpolador exclusivamente a quienes descienden por línea directa del gen profético, por entender la línea genética como proveedora de sabiduría e infalibilidad. Imponen, por tanto, un marco de positividad de fuente, pero positividad subjetiva, teocrático-imaginaria, en cuanto a la

islámica sean árabes, impulsando su carácter extranjero y buscándoles orígenes persas o indios, que es la leyenda urbana más dominante en Oriente, y fundada en la academia occidental, promovida, entre otros, por Rohallh Bahrami y Aezami (2014). Brockelmann (1960), como orientalista judío, niega el origen judío de Abū Hanīfa y se remonta a un origen iraquí babilónico. La literatura dominante, que es la que replica la leyenda urbana sembrada por el shíismo, se refiere a su origen afgano, como nacido en Kabul y asentado en Kufa (Iraq) desde la infancia (GAOJI, 1993, p. 47). Otros alegaron su origen iraquí cristiano de nacimiento, y que había sido bautizado, aunque su nieto había rechazado más tarde esta hipótesis (AL-HīŪN, 2007, p. 357). En cambio, existe una línea científica emergente que insiste en corroborar su origen babilónico y rechazar todo lo anterior (M'RŪF, 1977). 
hipotética infalibilidad del sujeto, y con ello la arbitrariedad de su raciocinio, y descartan así todo elemento epistemológico de deducción ni lógica ni retórica ni por analogía, tratándose simplemente de un pronunciado hermenéutico arbitrario e infalible, sin argumentación ni deducción. ${ }^{18}$ Además de ello, desde el inicio del presente decimocuarto siglo de la era islámica, es decir, desde la emergencia de la Revolución Islámica en Irán y la ostentación del poder teocrático, emergió una nueva escuela conocida como la deconstructivista, que pretende invocar una separación epistemológica entre la interpolación de las normas morales, religiosas reservadas a la razón genealógica, y aquellas referidas al pragmatismo sociopolítico (AL-H.KTIMĪ et al., 2015). La finalidad pretendida es una expansión de la potestad interpoladora a otros agentes del nuevo Estado recién implementado por la Revolución Islámica, que diera al poder político una potestad teocrática para interpolar —o usurpar — las normas de la religión con poder y potencial estadista.

\section{El colonialismo entre la epistemología y la identidad antropológica}

Lo que nos interesa hasta aquí es que los otomanos, una vez convertidos en potencia colonial dominante de los pueblos árabes, abrazaron la doctrina que más sembraba la crispación escolástica, pero que era flexible para su instrumentalización, es decir, la hanafista. Dado que la epistemología asentada por esta escuela se refería, como ya hemos comentado anteriormente, a la interpolación racional, la cual ofrece flexibilidad espacio-temporal al poder político para interferir en la religión e incidir en sus postulados como propios, o para introducirse en los pueblos al abrigo o entrelazada con la religión que ella misma ha usurpado y manejado a su conveniencia. Es decir, se convierte en instrumento político del poder al enturbiarse así la razón por el raciocinio político y, por tanto, postular el poder en nombre de la religión, pero en este caso un poder y una razón colonial extranjera que incide directamente en la identidad y la pertenencia de los pueblos subordinados. Impusieron así, y por la fuerza, su aplicación, con la exclusión de todas las demás, a los pueblos sometidos, fomentando sus estudios, la edición de su doctrina, y un amplio marco de apoyo público para su desarrollo en detrimento de las demás escuelas. Eso explica la huella geográfica

\footnotetext{
${ }^{18}$ Este método epistemólogo shíi de la infalibilidad fue resaltado por Alnasir (2020) como una insurrección cultural en la jurisprudencia iraquí desde 2003, por la sublevación de clases propiciada por la invasión norteamericana a Iraq que favoreció el alzamiento shíi, y con ello la sublevación epistemológica al derecho y la jurisprudencia. De pronto las resoluciones judiciales en Iraq se volvieron ambiguas, sin motivación, deducción ni discurso lógico, cada resolución es emitida en un solo párrafo que apenas resalta los hechos y el fallo decretado sin ningún razonamiento ni deducción (ALNASIR , 2020, p. 500).
} 
que acabó abarcando esta escuela, actualmente seguida desde Indonesia hasta Egipto. Precisamente en Egipto, el día siguiente de la invasión otomana, en 1517, Salim I impuso la epistemología hanafí como única, exclusiva y excluyente de cualquier otra, y disolvió todas las demás escuelas y tribunales preexistentes que seguían la epistemología shafií, nativa de Egipto, prohibiendo su uso en los tribunales egipcios (SALM, 1986, p. 15). Lo mismo había hecho en Iraq, aunque realmente Iraq era la cuna de todas las escuelas, además de fomentar las escuelas del hanafismo, que se centraron principalmente en Bagdad, excluyó estructuralmente todas las demás del poder.

Precisamente por esta razón, el shíismo safávida (persa) interpretó que el hanafismo era su primer rival, por ser el postulado y el instrumento del poder otomano. En consecuencia, lo primero hacia lo que los safávidas dirigieron su exterminio fue a esta escuela y a sus seguidores durante sus invasiones a Bagdad, como ya comentamos. Es decir, un colono usurpa una escuela y la impone a los pueblos subordinados, y llega otro colono, por su rivalidad político-colonial, toma a esa escuela por rival, y dirige su exterminio a los pueblos como seguidores de ella. La religión, sus escuelas y postulados epistemológicos se convierten no solamente en instrumento de poder, de denominación, ni tan solo en instrumento de poder colonial, sino también en instrumentos geopolíticos de confluencias coloniales en las que, de pronto, también los británicos entran en escena, concurriendo triangularmente con el mismo objetivo, como veremos enseguida.

Como consecuencia de ese concurso de confluencias surge otro movimiento nativo, de entre los propios denominados, que pone en jaque principalmente la doctrina colonial otomana y sus postulados religiosos. El wahabismo -así llamado por referencia a su fundador, al-Wahhab - surge a principios del siglo XVIII como movimiento de resiliencia sociocultural y lucha contra el postulado religioso de los otomanos. No emerge como escuela epistemológica como tal, sino que se postula como la más reciente de las escuelas epistemológicas, sin separarse de ninguna de las demás, pero poniendo en el centro de su diana al colonialismo otomano rescatando un principio de la doctrina islámica que excluye, por cuestión racial, a todo aquel que no sea árabe para liderar la nación islámica, es decir, se dirige directamente contra los otomanos. Ese postulado le convierte en blanco de los otomanos, pero a su vez en fértil instrumento para los británicos, quienes los apoyan en su lucha para debilitar con ello a los otomanos. Es decir, lo que es un instrumento de resiliencia nativa se vuelve en elemento de confrontación colonial delegada. 


\section{El sur de Iraq: el shíismo y la geoestrategia otomano-británica}

En el sur de Iraq se encuentran las tumbas de los venerados teóricos del shíismo y, por tanto, los shíitas aspiran a la dominación de estos yacimientos y constituir en torno a ellos su centro neurálgico, destino de peregrinación e imploración, lo cual para el wahabismo constituye una blasfemia, paganismo y huida de todo el paradigma islámico. Sin embargo, y a pesar de coincidir en eso con los otomanos en su antagonismo contra la ideología shíi, los wahabíes consideran a los otomanos colonos instrumentalizadores de la religión, lo que los coloca en el centro de su diana, por lo que no lograron aliarse y, por tanto, concurrir los tres en una batalla delegada para el interés estratégico británico, como veremos enseguida.

\section{Particularidad económica del shíismo e influencia británica}

Económicamente el shíismo tiene un esquema tributario distinto al islámico, ${ }^{19}$ pues los shíitas impusieron el llamado tributo de la quinta. Es decir, imponen a todos sus feligreses el pago anual de la quinta parte, el $20 \%$, de sus retribuciones y ganancias a favor de los miembros del clero, postulados como herederos del Profeta. ${ }^{20}$

Cole (1986) documenta el significativo aumento de la corriente imamita del shíismo —que es la epistemología patriarcal—, que desde el siglo XVI pasó de ser irrelevante a ser la dominante en todo el escenario iraquí, persa e indio debido a importante apoyo financiero y a las transferencias en efectivo hechas por la Compañía Británica del Este de la India entre 1786 y 1850 . Dichos recursos convirtieron al desierto en ciudades, y a estas en un peso pesado de recursos financieros por el volumen económico y migratorio que recibieron desde Persia y la India entre 1796 y 1904 (LITVAK, 2000). El tamaño de la transformación alcanzó tal nivel entre 1842-1850 que hacía imposible afrontarlo, al alcanzar el shíismo la tercera parte de la población de Bagdad y la total conversión del sur de Iraq (ÜSTÜN, 2007; NŪRĪ, 2019, p. 67).

\footnotetext{
${ }^{19} \mathrm{El}$ tributo general islámico sobre bienes se refiere al $2 \%$ sobre las ganancias del capital de inversión, a exclusión del capital vital y de manutención, que debe abonarse a la caja nacional del tributo islámico o, en su ausencia, repartirlo caritativamente a los necesitados más allegados.

${ }^{20}$ El pago de este impuesto es uno de los problemas más peliagudos que enfrenta a los Estados modernos con el shíismo. Los orientales lo supervisan con riguroso control, aunque sin éxito; sin embargo, los occidentales ignoran cabalmente este problema, y nadie se ha percatado de este asunto, dando lugar a un linchamiento sustantivo de los bienes del poder clerical shíi en Europa y Estados Unidos, y muy recientemente en América Latina.
} 
Dado que el sur de Iraq representa el escenario de paso de las tropas otomanas hacia el golfo y, por ende, a la India (ALNASIR, 2021), la interferencia británica para alterar la estructura demográfica y antropológica del sur de Iraq no solamente se limitó a estos elementos, sino que ha llevado incluso a modificar su ecosistema para favorecer mayores asentamientos y concentración shíi en el sur y conseguir así la falta de estabilidad y la fragmentación político-demográfica frente al Imperio otomano. En 1793, los británicos impulsaron el zanjamiento del canal de Babilonia, ${ }^{21}$ desde el Éufrates, para ampliar el espacio explotable, favorecer la agricultura y atraer así a mayores asentamientos de población shíi o conversa al shíismo en esa zona (NÜRĪ, 2019, p. 68). ${ }^{22}$

Además de impulsar la inmigración desde Persia y la India — sin embargo, estos pueblos no son árabes_- era mejor el pulso de las tribus de Arabia que se han movilizado hacia el norte huyendo del avance wahabí, avivado por los británicos también desde el sur. Las tribus huían del wahabismo, que luchaba contra las oligarquías tribales emergentes por la segmentación y el paganismo desde el desmantelamiento del Estado Islámico, que al llegar al norte —Iraq_, se encontraron con el shíismo, que hacía lo mismo, pero con mayor flexibilidad. Es decir, el shíismo mantenía las prácticas paganas y añadía otras, igualmente de paganas, pero conforme a su ideología, con el fin de conseguir mayor amasamiento de población y aumentar así su peso demográfico. La cuenca de Mesopotamia acabó presenciando no solamente la mutación demográfica y la antropológica, sino también la económica. Contemplando la figura 1 lo veremos enseguida.

\footnotetext{
${ }^{21}$ El aquí denominado canal de Babilonia se le conoce, y hasta la actualidad como Canal de la India, por referencia al proyecto indio de trasvase del Éufrates, y que además por propiciar el asentamiento de población india en la zona actualmente conocida como localidad de Al-Hindiya.

${ }^{22}$ A la corriente del saneamiento-blanqueamiento histórico colonial, que elogia el desarrollo tecnocrático de las naciones colonizadas, gracias al colonialismo, a la que nos hemos referido anteriormente, concretamente quien se refiere a las políticas de canalización de ríos (SATIA, 2007, p. 215), cabe preguntar sobre la finalidad espuria y el impacto sociopolítico (demográfico, identitario y antropológico) de tales proyectos a la vista de las perspectivas del presente artículo.
} 


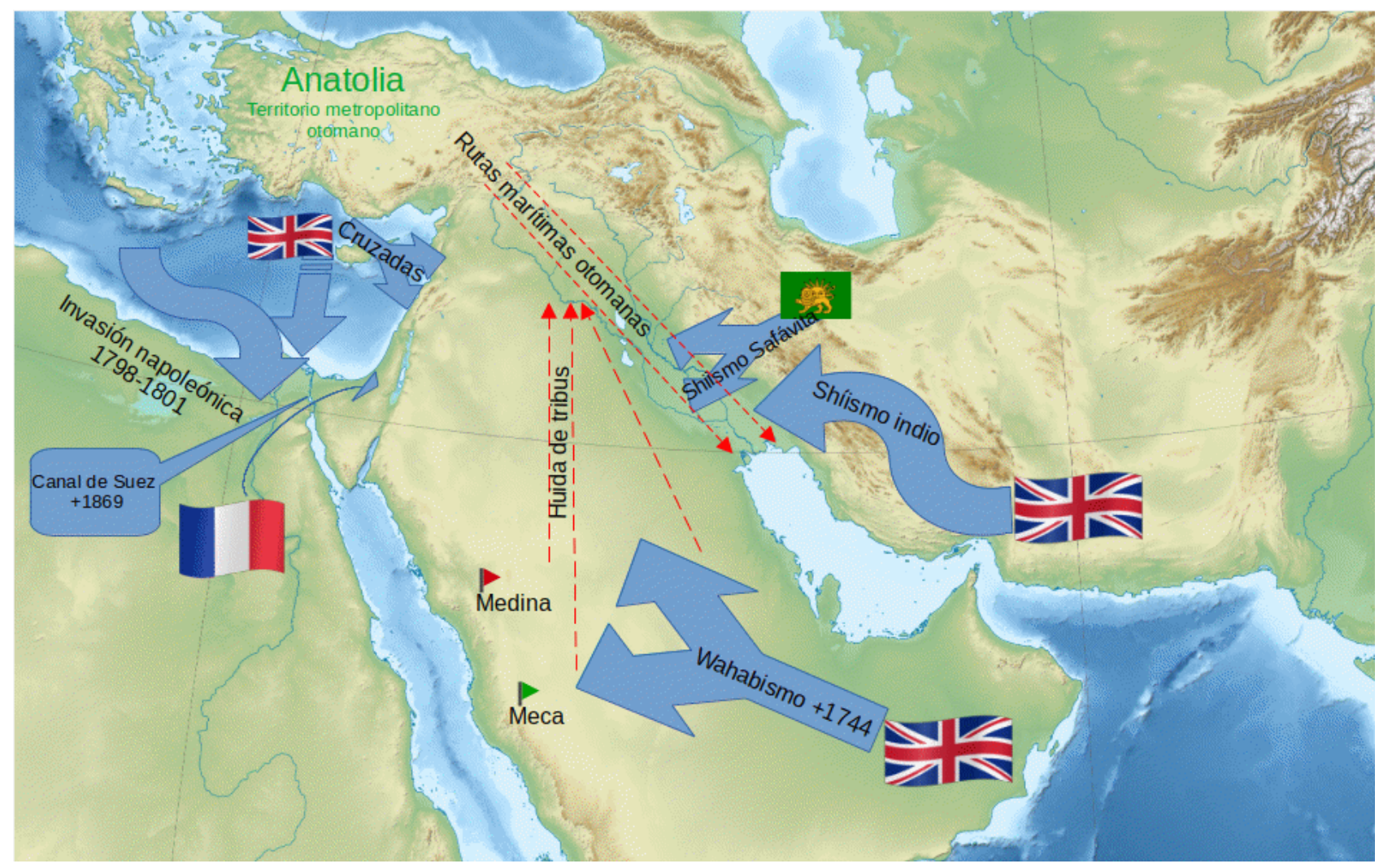

Figura 1: El concurso de confluencias coloniales y la movilización demográfica en Oriente Medio entre el siglo XVIl y el XIX.

\section{El Imperio otomano y el desequilibrio económico-antropológico}

El desequilibrio económico no se refiere tan solo al atesoramiento del capital proveniente de la India y el resto del mundo shíta, como se comentó anteriormente, sino también a otra artimaña otomana para paliar la situación, pues la movilización de las tribus del sur hacia el norte, además de buscar el pastoreo, les envolvió en miseria y de lucha por la sobrevivencia, dedicándose al saqueo de las vías comerciales, al entorpecimiento del comercio y a poner en jaque la estabilidad de la gobernanza otomana, que es precisamente lo que buscaban los británicos. Para resolver este problema, y dada la expansión de la huella fértil por la canalización de nuevos ríos con el dinero proveniente de la India, los otomanos optaron por asentar las tribus concediéndoles vastas tierras para su asentamiento permanente y con el fin de lograr así ganar su alianza. Pero además, y para asegurar esta gobernabilidad, concedieron estas inmensas tierras a título de propiedad individual a los jefes tribales, que se convirtieron en terratenientes, pasando así del sistema tribal al monopolio capitalista y a costa del resto del pueblo, que acaba descendiendo a clase 
campesina y subordinada. Los miembros de las tribus pasaron del synoiquismo antropológico a la subordinación y al vínculo con la tierra como fuente de ingreso, anclaje y propiedad del jefe de la tribu, que pasa a ser el terrateniente en una nueva estructura de sociedad estamental impulsada por las confluencias coloniales.

La mutación alcanzó incluso a la estructura intelectual. Por un lado, el pulso shíita, hinchado por los recursos financieros que recibía, inició la creación de escuelas shíitas donde arraigaban la doctrina y la alineación sociocognitiva e identitaria con el shíismo ante el vacío de poder educativo otomano, ya que los otomanos mantenían los pueblos subordinados en la agonía del salvajismo y la ignorancia. ${ }^{23}$ En contrapartida, para las tribus recién asentadas, los otomanos crearon en 1892, en Estambul, una escuela específica llamada Escuela de Tribus, en la que reclutaban a los hijos de los jefes tribales (ROGAN, 1996), ${ }^{24}$ convertidos en nueva clase de terratenientes, y les daban formación y educación para asegurar la alineación de las siguientes generaciones y la creación de una clase aristocrática conforme a sus intereses coloniales. ${ }^{25}$ El pueblo llano acabó segmentado entre el lastre de la ignorancia, la conversión al shíismo y la subordinación de la nueva clase sociopolítica alineada con los otomanos, cuando en realidad ambas son confluencias dominantes, agentes coloniales e impulsadas por potencias extranjeras. ${ }^{26}$

\footnotetext{
${ }^{23}$ El proselitismo educativo del shíismo es una de sus herramientas más fuertes hasta la actualidad. Ha sido rescatada e re-implementada como política de conversión al shíismo por la Revolución iraní desde 1979, y junto a ella actualmente la iraquí desde 2003, se basa en la implementación de escuelas como centros educativos caritativos en otros países, con los que inculca el adoctrinamiento de las generaciones y su conversión posterior al shíismo. Igualmente lo es el sistema de becas dirigido a investigadores occidentales para cursar estudios en Irán y convertirlos así en afines a su doctrina en ramas específicas que sirvan de enlace en sus nuevas sociedades, como el periodismo, las ciencias políticas y las sociales. Una fórmula de colonialismo mental de las generaciones.

${ }^{24}$ La Escuela de Tribus de Estambul, creada en 1892, alcanzó el año siguiente la cifra de unos 210 alumnos procedentes de Arabia, Libia, Iraq, Siria, además de kurdos de varias provincias y albaneses (ROGAN, 1996, p. 87-88). Los artículos 9 y 10 de su estatutos dejan bien claro los objetivos de la escuela y, a los efectos de lo que nos interesa aquí, dicen: El objetivo principal de crear la escuela se propone hacia la capacitación de los hijos de las tribus para participar en el progreso a través del conocimiento y la aculturación, además de arraigar en ellos su alineación con el patriarcado otomano y la ostentación del Imperio islámico, y afianzar su fidelidad con las políticas del Estado y el futuro empeño que se les requerirá para llevar acabo la gobernanza según los preceptos imperiales. [...]

Al finalizar sus estudios, se les entregará un diploma para que, al regresar a sus tribus, trabajen como maestros en las escuelas que se pretenden abrir en sus pedanías, o en los servicios que se entablarán según los proyectos civilizadores del Estado. La traducción del inglés es nuestra, a partir del texto de Rogan (1996, p. 87) y corroborada con la versión árabe de Rogan (2014, p. 27), quien lo hace desde la versión original de la gaceta otomana en turco antiguo.

${ }_{25}$ Uno de los síntomas de la colonialidad que define Quijano es la seducción intelectual con el colonialismo, impulsada por el lavado de cerebro de las generaciones mediante sistemas de becas y reclutamiento en la metrópolis colonial para asegurar la narrativa y la alineación intelectual futura con los intereses coloniales y su fantasía histórica (QUIJANO, 1992).

${ }^{26}$ En la teoría hegeliana de las raíces históricas para que una nación tenga presencia histórica y vocación de progreso se condiciona a la "existencia de una clase social capaz de generar en cada momento histórico la
} 
Cuando el Imperio otomano quiso afrontar la situación, lo hizo con el peor remedio, inventando una escuela con el mismo estilo y la misma política segregacionista que el adversario el shíismo; pero, en ese caso, más punzantemente, al inducir al clasismo social y potenciar la estratificación estamental. ${ }^{27}$ No fue en absoluto una iniciativa caritativa ni proyectada por el bienestar y el forjamiento social (ROGAN, 1996, p. 87), sino propuesta para la seducción, el lavado de cerebros y la creación de instrumentos leales con las políticas coloniales dentro de la población, como masas intelectuales potencialmente alineadas con sus intereses y para forzar y mantener la inmersión del pueblo en la ignorancia y la denominación. De hecho, en la selección del alumnado ni siquiera se tenía en cuenta a los hijos de todas las tribus recién asentadas, sino que se ordenó la selección minuciosa de los hijos de unas tribus que se consideraban más nobles y propicias a la fidelidad con el Imperio otomano, cuyos hijos deberán ser favorecidos en la selección e instruidos en detrimento de otros. Así, mediante orden al comandante general de sexto ejército otomano en Basura, al sur de Iraq, se le refiere que "la tribu de los Al-s 'dūnï̈ 'Al-Saadoun' son los jefes más nobles respecto de las demás tribus y, considerando que son de una sola familia, sus hijos deberán recibir el mayor honor de selección" (ROGAN, 2014, p. 28). ${ }^{28}$

Al poco tiempo, por la debilidad y el posterior derrumbe del Imperio otomano, sus políticas dejaron sus lastres impregnados en la estructura demográfica, antropológica y sociopolítica de las sociedades residuales. Las tribus emergieron como subversiones estatales, con poderes y estructuras, además de las económicas, militares y las de justicia. Aunque muchos antropólogos se interrogan sobre la estructura interna de las tribus (GELLNER, 1969, 2008; HAMMOUDI, 1980), los británicos, a su llegada a Iraq se encontraron con un vacío abstracto de poder, hasta el punto de que las tribus eran quienes ostentaban la justicia penal, en muchos casos aplicando la ley del más fuerte. El nuevo poder colonial británico no hizo otra cosa que imponerles la obligación de comunicar al puesto administrativo más próximo el lugar y fecha de celebración de los tribunales tribales y los veredictos acordados (ALNASIR, 2019, p. 64; GELLNER, 2008, p. 16). Es decir, de sumisión en sumisión, la

cultura nacional" (GARCÍA PELAYO, 1981, p. 49). Sin embargo, en este caso, el colonialismo condicionó el futuro de las generaciones de los pueblos subordinados mediante la inseminación de una clase social condenada a renovar en cada momento histórico la subordinación cultural y la esquizofrenia identitaria.

${ }^{27}$ Otro de los síntomas de la colonialidad definida por Quijano (2007) es la siembra de la estratificación social por las políticas coloniales mediante la seducción de fragmentaria y la inducción selectiva de clases.

${ }^{28}$ Efectivamente, uno de los egresados de esta familia, Abdul-Muhsin Al-Saadoun, llegó a ser posteriormente el primer primer ministro de Iraq tras la formación del Reino de Iraq en 1921, así como otros miembros de la familia Al-Saadoun se convirtieron — y así hasta la actualidad — en los decanos de la clase intelectual iraquí. 
segregación y el egocentrismo identitario se consolidaban cada vez más hasta formar un insuperable dique ante los nuevos Estados formados después del colonialismo.

\section{Conclusiones}

La religión, en Oriente Medio, engloba el referente central de la identidad colectiva más que un esquema ideológico-normativo. La intervención colonial y su instrumentalización de la religión la convirtieron en el instrumento más punzante con el que ha jugado el colonialismo. La apropiación de sus instrumentos epistemológicos, su usurpación y camuflaje la convirtió en un centro vibrante de la identidad colectiva, y con ello el conjunto de los individuos acabó tambaleándose entre las interferencias extranjeras y los poderes entrelazados, entruyados, privándoles del modo de encontrarse una decisión o un arraigo o hasta una definición individual del yo. Además, y en uso del mismo instrumento, la religión, las confluencias de las potencias coloniales acabaron con el tejido demográfico e identitario de los pueblos nativos convirtiéndolos en escudos humanos para los intereses coloniales.

El colonialismo se ha proyectado contra las religiones orientales convirtiéndolas en residuos de colonialidad. A los cristianos orientales se les indujo la identidad religiosa como nación, impulsando que abrazaran el ideal nacionalista europeo con eje religioso. ${ }^{29}$ Es decir, cuando a los musulmanes se les desarticula la religión, a los cristianos orientales se los farolea con el mismo paradigma a la inversa, convirtiéndoles en un enclave demográfico dentro del conjunto de las comunidades orientales y reduciéndolas a comunidades de disociados. El papel de los europeos en la fragmentación cristiana entre las comunidades otomanas creó un enclave de colonialidad para la interferencia extranjera, pero causando la esquizofrenia interna de este enclave (EDIB, 1930, p. 66). Los cristianos de Oriente se volvieron un instrumento colonial de las potencias extranjeras. Baron de Tott, el genio de la invasión francesa de Egipto, en las conclusiones finales de su proyecto, en 1777, se refirió a instrumentalizar a los cristianos orientales a favor del colonialismo francés a cambio de unas tierras y una vida dulce que les hará adherirse fielmente a los colonos y sus intereses (CHARLES-ROUX, 1929, p. 27). De hecho, y a su vez, el mismo Tott, refiriéndose a los

\footnotetext{
${ }^{29} \mathrm{La}$ interpretación de Edib se refiere a que el idealismo poswestfálico europeo fue recibido en el Imperio otomano en dos direcciones, los turcos lo abrazaron desde la perspectiva de democracia y libertad política, mientras que los cristianos, inducidos por los propios europeos desde el ángulo de defensa de minorías e identidades nativas, se agarraron al nacionalismo como identidad religiosa, que era todo lo contrario a aquello en lo que realmente consiste el westfalismo, y en dirección inversa a lo que hicieron con los musulmanes (EDIB, 1930, p. 66).
} 
musulmanes de Egipto, concluyó con que son "beduinos, no tienen del islam más que el nombre, hay muchos cristianos coptos, aspiran la dominación cristiana" que se deben instrumentalizar (CHARLES-ROUX, 1929, p. 52).

Las naciones residuales del colonialismo hispánico lograron definirse e identificar el catolicismo como instrumento colonial, algunos incluso lo rubricaron exactamente como religión colonial, iglesias o templos coloniales, aunque este difiere sustancialmente del caso oriental comentado. En cambio, y por razón propia de las religiones orientales y las estructuras antropológicas árabes, las comunidades nativas nunca lograron volver a cohesionarse en sociedades integradas ni a conformar una entidad política forjada y adherida a la emergente estructura política poscolonial definida como Estados nacionales. La religión, entendida como referente de identidad utópica anticolonial, se ha vuelto en residuo de colonialidad y, con ello, la identidad se torna identidad poscolonial postiza. La comparativa lo corrobora, el islam resultante del colonialismo en Argelia es muy ajeno y diferente al también llamado islam poscolonial en la India, y ninguno tiene que ver con el islam seguido en Arabia (SCHACHT, 1982, cap. 11). Y a pesar de ello, todas estas comunidades luchan por identificarse con la rúbrica religiosa como símbolo de su identidad y pertenencia utópica y por aversión a la identidad política impuesta geométricamente como agencia colonial, ignorando que realmente la religión con la que hipotéticamente se están identificado es igualmente (pos)colonial, es una identidad colonial y un futuro abanderado por los hijos y clases encadenados por el colonialismo. Esta interpretación explica el cruce de datos de los resultados de la encuesta del World Values Survey (WVS), en cuanto a la identidad-pertenencia religiosa frente a la militancia en una organización o institución religiosa. En la muestra, del 2010-2014, el 90,7 \% de los argelinos declara que la religión es un valor importante en su vida, al igual que lo hace el 93,8 \% de los egipcios, el 93,3\% de los jordanos, el $84,7 \%$ de los iraquíes, el $88,9 \%$ de los marroquíes, el $87,5 \%$ de los palestinos, el $95,4 \%$ de los tunecinos y el 68,1\% de los turcos. Sin embargo, el 91,7 \% de los argelinos, el 99,2 \% de los egipcios, el 89,2 \% de los jordanos, el $90 \%$ de los iraquíes, el 91,9 \% de los marroquíes, el $82,0 \%$ de los palestinos, el 98,4 \% de los tunecinos y el 97,3 \% de los turcos se declaran ajenos y no afiliados a ninguna organización religiosa (World Values Survey, 2010-2014, v. 25). Veamos mejor en la figura 2. 


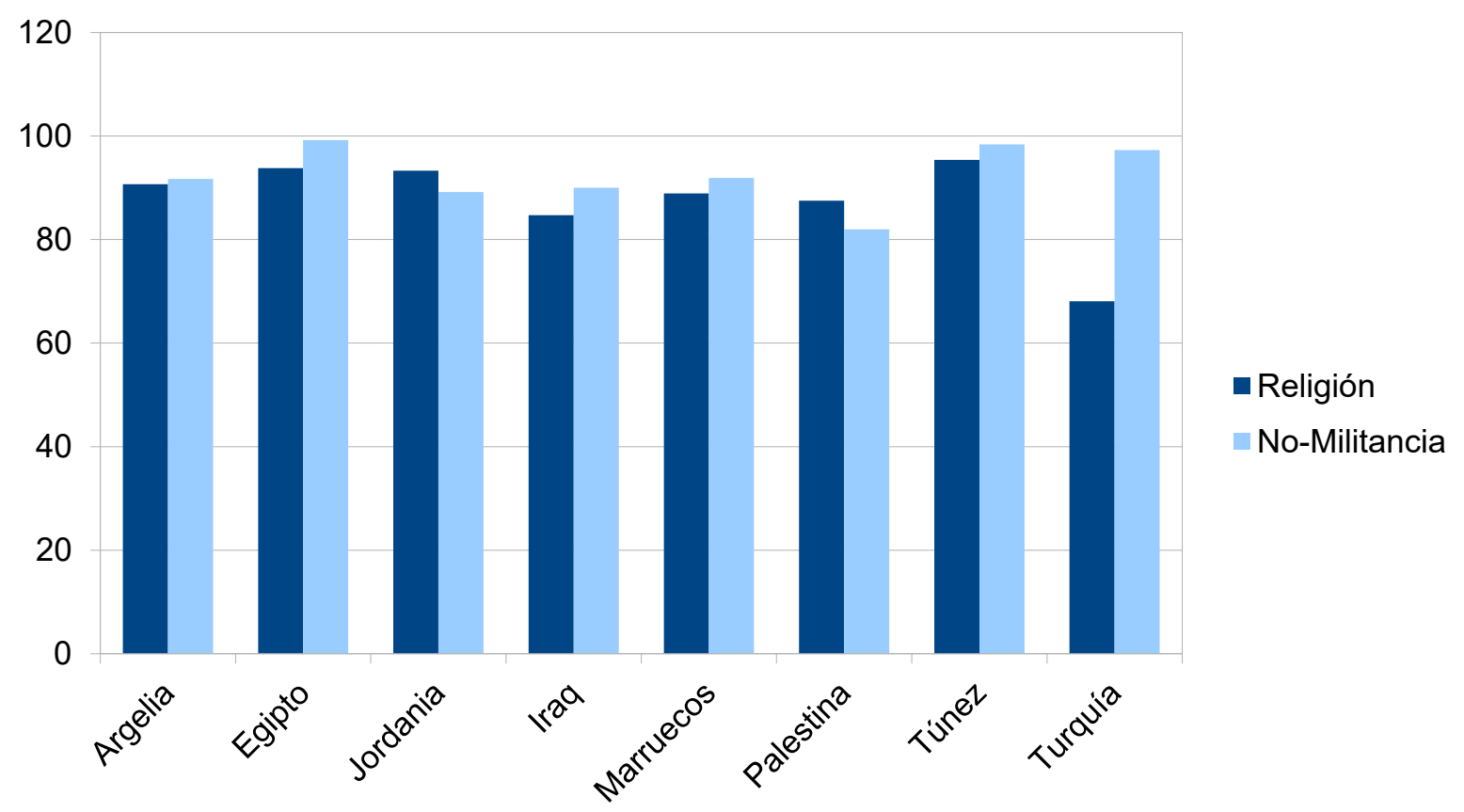

Figura 2: La importancia de la religión como valor identitario vs. la no militancia en organización de oligarquía religiosa (World Values Survey, 2010-2014, v. 9 vs. v. 25)

El poscolonialismo oriental agoniza en un laberinto de identidad difusa al ignorar la intersubjetividad de sus relaciones con el (pos)colono y las de su propia identidad. Se define con algo, entendido como propio, en huida de la estructura poscolonial, cuando realmente ese instrumento se debe igualmente a un camuflaje colonial que le había sido incrustadoentruyado colonialmente. El colonialismo no dejó margen de resiliencia a las comunidades condenadas a la fragmentación, sumergidas en un (pos)colonialismo híbrido (VIEIRA, 2019), astuto y alternante, que ha ido desplazando los pueblos hacia una identidad diáfana, quedando errantes entre huir de la religión como estructura clerical oligárquica, buscando una estructura arreligiosa, estadista, olvidando que la religión es su referente de identidad social, grupal y de pertenencia cognitiva. Los pueblos se quedaron atrapados en un laberinto entre Estados impuestos geométricamente sin forjamiento sociocognitivo y entes tribales y estamentales sin estructuras orgánicas que minan su identidad antropológica, además de un imaginario de colonialidad proyectado distópicamente contra su utopía identitaria, sumergiéndolos en una esquizofrenia crónica. 


\section{Referencias}

ABDEL RAZIQ, Ali. الإسلام واصول الحكم [Los principios de la gobernanza en el islam](III). Cairo: Al-mṭb $\ddot{t}$ al-mșrït, 1925.

ABU-LUGHOD, Leila. Zones of Theory in the Anthropology of the Arab World. Annual Review of Anthropology, v. 18, p. 267-306, 1989.

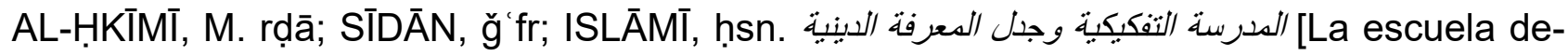
constructivista y la meditación religiosa]. Beirut: Alintishar, 2015.

ALLAL, Amin; GEISSER, Vincent. La Tunisie de l'après-Ben Ali. Les partis politiques à la recherche du «peuple introuvable». Cultures \& Conflits, n. 83, p. 118-125, 2011. https://doi.org/10.4000/conflits.18216

ALNASIR, Samer. Concepto jurídico, Religión y Secularidad: Los casos de Israel, Egipto e Iraq. Madrid: Universidad Carlos III de Madrid, 2019.

ALNASIR, Samer. Calamidades del Derecho (post)Colonial y su Orientalismo: Religión, Identidad y libertad individual en Egipto, Iraq y Túnez. Boletín Mexicano de Derecho Comparado, $\mathrm{n}$. 158, p. 485-519, mayo/agosto 2020. https://doi.org/10.22201/iij.24484873e.2020.158.15627

ALNASIR, Samer. Introspección antropológica en las prácticas y usos sociales, religiosos, identitarios y de colonialidad entre Egipto, Iraq y Siria. Anales de Antropología, v. 55, n. 2, p. 195-209, 2021. https://doi.org/10.22201/iia.24486221e.2021.78433

AL-ֵIIŪN, Ršīd. الأديان والعذ/هب بالعراق [Las religiones y sectas en Iraq]. Kolen \& Bagdad: Alkamel Verlag, 2007.

BAYART, Jean-François. Etudes postcoloniales (Les) : un carnaval académique. Paris: Karthala, 2010a.

BAYART, Jean-François. Les études postcoloniales : un carnaval académique. Politique étrangère, n. 4, p. 912-918, hiver 2010b. https://doi.org/10.3917/pe.104.0912

BECCARIA, Cesare. Über verbrechen und strafen. Frankfurt am Main: Insel Verlad, 1988.

BÉZIAU, Jean-Yves. Quine on identity. Principia: An International Journal of Epistemology, v. 7, n. 1-2, p. 1-15, 2003. Available at: http://www.jyb-logic.org/Quine\%20on\%20identitynew\%20version.pdf. Accessed on: May 23, 2021.

BROCKELMANN, Carl. History of the Islamic Peoples. Translated by Joel Carmichael e Moshe Perlmann. New York: Capricon, 1960.

BOUDERBALA, Négib; PASCON, Paul. Le droit et le fait dans la société composite : essai d'introduction au système juridique marocain. Bulletin économique et social du Maroc, $\mathrm{n}$. 117, p. 1-17, 1970. Disponible sur : https://docplayer.fr/191377014-Le-droit-et-le-fait-dansla-socie-composite-essai-d-introduction-au-systeme-juridique-marocain.html. Consulté le : 23 mai 2021. 
CASTILLO RAMÍREZ, Guillermo. La propuesta de proyecto de nación de Gamio en Forjando Patria (pro nacionalismo) y la crítica del sistema jurídico- político mexicano de principios del siglo XX. Desacatos: Revista de Ciencias Sociales, n. 43, p. 111-126, 2013. https://doi.org/10.29340/43.112

CHARLES-ROUX, François. Le projet français de conquête de l'Egypte sous le règne de Louis XVI. Caire: Imprimerie de I'Institute Français, 1929.

COKE, Richard. Baghdad, the city of peace. London: T. Butterworth, 1927.

COLE, Juan. R. I. «Indian Money» and the Shi'i Shrine Cities of Iraq, 1786-1850. Middle Eastern Studies, v. 22, n. 4, p. 461-480, 1986. https://www.jstor.org/stable/4283138

CONSTANTINE, Stephen. The Making of British Colonial Development Policy 1914-1940. London: Taylor \& Francis, 2005.

DENEAULT, Alain. La médiocricité. Québec: Lux, 2015.

EDIB, Halide. Turkey Faces West. New Haven: Yale University Press, 1930.

GALLEGO GARCÍA, Elio. Tradición jurídica y derecho subjetivo. Madrid: Dykinson, 2005.

GAMIO, Manuel. Forjando pátria. Traducido por Fernando Armstrong-Fumero. Mexico: Porrúa, 1982.

GAOJI, Wehbe Suleiman. أبو حنيفة النعمان [Abu Hanifa al Numán]. Damasco: Dār al-qlm dmšq, 1993.

GARCÍA PELAYO, Manuel. El tema de las nacionalidades: la teoría de la nación en Otto Bauer. Madrid: Pablo Iglesias, 1981.

GELLNER, Ernest. Système tribal et changement social en Afrique du Nord. Annales Marocaines de Sociologie, n. 2, p. 3-19, 1969.

GELLNER, Ernest. Naciones y nacionalismo. Traducido por Javier Seto. Madrid: Alianza, 2008.

GROSSI, Paolo. Europa y el Derecho. Traducido por Luigi Giuliani. Madrid: Crítica, 2007.

HAMMOUDI, Abdellah. Segmentarity, social stratification, political power and sainthood: reflections on Gellner's theses. Economy and Society, v. 9. n. 3, p. 279-303, 1980. https://doi.org/10.1080/03085148008538598

HEIKAL, Mohamed Hassanein. العقد النفسية التي تحكم الشرق الأوسط [Los traumas psicologicos gobernantes de oriente medio]. Cairo: Arab Press Co, 1958.

HENRY, Jean-Robert. L'imaginaire juridique d'une société mutant. In : FLORY, Maurice; HENRY, Jean-Robert; MAHIOU, Ahmed (Org.). La Formation des normes en droit international du développement. Paris: CNRS, 1984. p. 29-40. 
KASER, Max. Las Interpolaciones en las fuentes jurídicas romanas. Traducido por José María Coma y Götz Gallenkamp. Granada: Comares, 1998.

KELSEN, Hans. Teoría pura del Derecho. Traducido por Moisés Nilve. Buenos Aires: Eudeba, 2000.

LEED, Eric J. No Man's Land: combat and identity in World War 1. Cambridge: CUP Archive, 1979.

LITVAK, Meir. The Finances of the 'Ulamā' Communities of Najaf and Karbalā', 1796-1904. Die Welt Des Islams, v. 40. n. 1, p. 41-66, 2000. https://www.jstor.org/stable/1571103

LONGRIGG, Stephen Hemsley. Four centuries of modern Iraq. Oxford: Oxford Clarendon Press, 1925.

MALDONADO-TORRES, Nelson. Sobre la colonialidad del ser: contribuciones al desarrollo de un concepto. In: CASTRO-GÓMEZ, Santiago; GROSFOGUEL, Ramón (Ed.). El giro decolonial: reflexiones para una diversidad epistémica más allá del capitalismo global. Bogotá: Siglo del Hombre Editores, 2007. p. 127-167.

MARTIN, Denis-Constant. À la quête des OPNI (objets politiques non identifiés). Comment traiter l'invention du politique? Revue française de science politique, v. 39. n. 6, p. 793-815, 1989. https://doi.org/10.3406/rfsp.1989.394448

M'RŪF, Nāḡī. عروبة الإمام أبي حنيفة النعمان [Las raíces árabes del Imam abu hanifa al numán]. In: Conferencia de la historia islámica. Cairo: Universidad del Cairo, 1977. No paginado. Disponible en: https://web.archive.org/web/20160304133706/http://arareaders.com/books/details/8795. Consultado en: 22 mayo 2021.

MITCHELL, Timothy. Rule of Experts: Egypt, Techno-Politics, Modernity. Berkeley: University of California Press, 2012.

NOUSIAINEN, Kevät. Las interacciones del derecho. In: AARNIO, Aulis; GARZÓN VALDÉS, Ernesto; UUSITALO, Jyrki (Org.). La normatividad del derecho. Barcelona: Gedisa, 1997. p. 141-160.

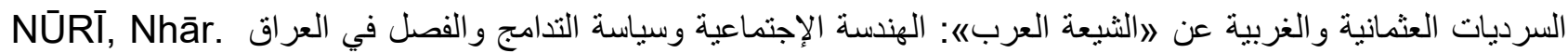
Los relatos otomanos y occidentales sobre los shías árabes: la ingeniería social y las políticas de inmersión y segregación en la última época otomana en Iraq. In S 'īD, Hīdr (Org), الشبعة العرب: الدواطَنة والهوية [los shías árabes: la identidad y la ciudadanía]. Beyrouth: Arab Research Institute, 2019. p. 64-93.

ORTEGA Y GASSET, José. España Invertebrada. Madrid: Revista de Occidente, 1921.

PARSONS, Terence. Entities without identity. Philosophical Perspectives, n.1, p. 1-19, 1987. https://doi.org/10.2307/2214141 
POPPLEWELL, Richard. British intelligence in Mesopotamia 1914-16. Intelligence and National Security, v. 5, n. 2, p. 139-172, 1990. https://doi.org/10.1080/02684529008432050

QUIJANO, Anibal. Colonialidad y Modernidad/Racionalidad. Perú Indígena, v. 13, n. 29, p. 11-20, 1992. https://www.lavaca.org/wp-content/uploads/2016/04/quijano.pdf

QUIJANO, Anibal. Colonialidad del Poder y Clasificación Social. In: CASTRO-GÓMEZ, Santiago; GROSFOGUEL, Ramón (Org.). El giro decolonial: reflexiones para una diversidad epistémica más allá del capitalismo global. Bogotá: Siglo del Hombre, 2007. p. 93-126.

QUINE, Willard van Orman. Word and Object. Massachusetts: Massachusetts Institute of Technology, 1960.

ROGAN, Eugene. Aşiret Mektebi: Abdülhamid II's School for Tribes (1892-1907). International Journal of Middle East Studies, v. 28. n. 1, p. 83-107, 1996. https://doi.org/10.1017/S0020743800062796

ROGAN, Eugene. مدرسة العشائر في اسطنبول [la escuela de tribus en Estambul]. Traducido por Nhār Nūrī. Bagdad: Alwarrak, 2014.

ROHALLH BAHRAMI, Broum; AEZAMI, Pour. A study of intellectual-cultural aspects of Abu Hanifa Ahmad Ibn Davood IbnVanand Dinavari. Elixir Economics, n. 67C, p. 21755-21765, $2014 . \quad$ Disponible en: https://www.elixirpublishers.com/articles/1402903974_67C\%20(2014)\%2021755-21765.pdf. Consultado en: 23 mayo 2021.

SALLM, Lṭyfẗ mḥmd. النظام القضائي الهصري الحديث [el sistema judicial moderno en Egipto]. Cairo: Dạr ạlsh̆rwq, 1986. v. 1.

SATIA, Priya. Developing Iraq: Britain, India and the Redemption of Empire and Technology in the First World War. Past \& Present, v. 197. n. 1, p. 211-255, 2007. https://doi.org/10.1093/pastj/gtm008

SCHACHT, Joseph. An Introduction to Islamic Law. New York: Clarendon, 1982.

TAJFEL, Henri. Human groups and social categories: studies in Social Psychology. Cambridge: Cambridge University Press, 1981.

ÜSTÜN, İsmail. The Hopeless Struggle of The Ottomans Against The Spread of S hi' a in The 19th Century Province of Baghdad. Marmara Üniversitesi Ilahiyat Fakültesi Dergisi, v. 33. n. 2, p. 69-86, 2007. Disponible en: https://dergipark.org.tr/tr/download/articlefile/162726. Consultado en: 24 mayo 2021.

VIEIRA, Marco. The decolonial subject and the problem of non-Western authenticity. Postcolonial Studies, $\quad$ v. $22 . \quad$ n. $2, \quad$ p. $150-167, \quad 2019$. https://doi.org/10.1080/13688790.2019.1608795

WORLD VALUES SURVEY. Online Data Analysis. Available at: https://www.worldvaluessurvey.org/WVSOnline.jsp. 2010-2014. Accessed on: 11 feb. 2021. 
Passagens: Revista Internacional de História Politica e Cultura Jurídica

Rio de Janeiro: vol. 13, ${ }^{0}$ 3, setembro-dezembro, 2021, p. 389-418.

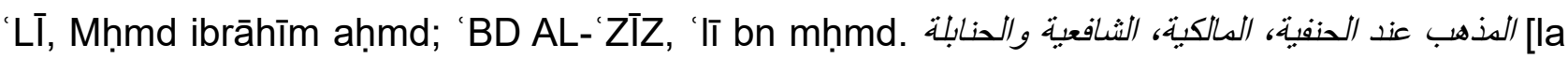
escuela en los hanafís, malekitas, shafií y hanbalíes]. Kuweit: Al-ūī al-islāmī, 2012. 